Original Research Paper

\title{
Jute Production in Bangladesh: A Time Series Analysis
}

\author{
${ }^{1}$ Md. Moyazzem Hossain and ${ }^{2}$ Faruq Abdulla \\ ${ }^{1}$ Department of Statistics, Jahangirnagar University, Savar, Dhaka-1342, Bangladesh \\ ${ }^{2}$ Department of Statistics, Islamic University, Kushtia-7003, Bangladesh
}

\author{
Article history \\ Received: 30-03-2015 \\ Revised: $28-04-2015$ \\ Accepted: 19-11-2015 \\ Correspondings Author: \\ Md. Moyazzem Hossain \\ Statistics, Jahanirnagar \\ University, Bangladesh \\ E-mail: mmhmm.justat@gmail.com
}

\section{Introduction}

In Bangladesh, the service sector accounts for $51 \%$ of GDP, the industrial sector $30 \%$ and agriculture $18 \%$. Bangladesh is a major agricultural producer, particularly in the global production of rice (4th), fisheries (5th), jute (2nd), tea (10th) and tropical fruits (5th) (Stephen and Abir, 2014). That is, Bangladesh is currently the second largest producer of jute fiber, now over taken by India. After the country's independence, more than $80 \%$ of total foreign currency in Bangladesh was earned from jute and jute related goods. But after 80's, the earning rate of foreign currency from jute industry has gradually declined. The sector provides about $10 \%$ of the total employment in the economy and $12 \%$ of GDP. About $90 \%$ of jute products produced in Bangladesh is exported (Rahman, 2001). Foreign exchange earnings of Bangladesh come mostly from jute. Beside, jute is a good source of revenue for the governments in the form of taxes, levies, sales tax, octroi and custom duties on jute goods (Sikdar and Banerjee, 1990). Bangladesh is famous for jute production and earned a big amount of foreign currency by exporting jute and jute products to different countries. At one stage, Jute was only the vital sector in Bangladesh from which major portion of foreign currency is to come and help Bangladesh's economy and a large number of manpower were employed there. Bangladesh was recognized as one of the best jute producing and exporting countries of the world (Islam et al., 2013). Over the last 20-25 years it did slide down to the seventh position. Now it regained to come to the forth position (Abdullah, 2013).

Jute is called the Golden Fiber of Bangladesh. The Jat Area, popular for highest quality of jute fiber is located in Bangladesh. Therefore, Bangladesh is able to supply the highest quality of jute fiber in the world. However, Bangladesh falls behind its other competitors in applying recent technological advancements. In terms of world export of jute fiber, Bangladesh's share is more than $70 \%$, which makes Bangladesh the largest exporter of jute fiber in the world (http://en.wikipedia.org/wiki/Jute_cultivation). Jute is grown mainly in Bangladesh for fiber rather than for seed. In Jute, use of quality seeds of improved variety alone contributes $223.54 \mathrm{~kg}$ of extra fiber per hectare i.e. an increase of about 17\% (Talukder and Rahman, 1989). It is one of the cheapest and the strongest of all natural fibers and considered as fiber of the future. Jute is second only to cotton in world's production of textile fibers. India, Bangladesh, China and Thailand are the leading producers of Jute. It is also produced in southwest Asia and Brazil. India is the largest producer 
of jute goods in the world, while Bangladesh is the largest cultivator of raw jute (Ghosh and Jethi, 2013).

Islam and Alauddin (2012) have pointed out the fluctuations and declining growth trend of jute production in the world and have created a good opportunity for countries like Bangladesh. Jute, as a natural fiber, has many inherent advantages like lustier, high tensile strength, low extensibility, moderate heat and fie resistance and long staple lengths. It is a biodegradable and eco-friendly. It has many advantages over synthetics and protects the environment and maintains the ecological balance. Jute is not only a major textile fiber but also a raw material for non-traditional and value added non-textile products. Jute is used extensively in the manufacture of different types of traditional packaging fabrics, manufacturing Hessian, carpet backing, mats, bags, tarpaulins, ropes and twines. Recently jute fibers are used in a wide range of diversified products: decorative fabrics, chic-saris, salwar kamizes, soft luggage's, footwear, greeting cards, molded door panels and other innumerable useful consumer products (Ghosh and Jethi, 2013). Jute is an annually renewable resource with a high biomass production per unit land area, and jute products being biodegradable decompose in the soil at the end of product life-cycle. Towards global warming, the synthetic materials are being considered as the root of many problems while the natural fiber products are proven to be absolutely harmless (Environment, 2011). The jutes increase the fertility of land, preserve the ozone layer by absorbing $\mathrm{CO}_{2}$ and clean the air by emitting $\mathrm{O}_{2}$. The jute is used as vegetable, geotextile, biogas, biodegradable products which have impact on the environment (Islam and Ahmed, 2012). In jute production system, water management includes application of irrigation and draining out the excess water is needed from the jute fields. Irrigation is the artificial application of water to the crop field for its proper growth (Rahman et al., 1992).

In Bangladesh, almost 3 million farming households are involved in jute cultivation. Jute harvesting takes place at a time when marginal farmers and farm workers are faced with shortage of their food stocks. The cash derived from sales of jute fiber and the wages received by workers are an important contribution to food security for this vulnerable segment of the population. Rapid employment generation is vital to poverty reduction in Bangladesh. Economic growth driven by sectors that are labor-intensive by nature has greater potential for job creation. The fact that the jute sector is so labor-intensive has played important strength, given the country's large rural underemployment (Abdullah, 2013). The global demand for jute and allied products has seen a steady increase driven by a fresh comeback for biodegradable fiber as people now look for ecofriendly products replacing synthetics. Bangladesh produces around $30 \%$ of the total world production of jute and exports around $40 \%$ of its total produce as raw jute. Thus, it is necessary to estimate the behaviors of jute production and forecast the future production of jute in Bangladesh. The main purpose of this paper is to identify the Auto-Regressive Integrated Moving Average (ARIMA) model that could be used to forecast the jute production in Bangladesh.

\section{Materials and Methods}

\section{Data Source}

This study considered the published secondary data of yearly jute production in Bangladesh which was collected over the period 1972 to 2013 from the Food and Agricultural Organization (FAO) website.

\section{ARIMA Model}

Suppose that $\left\{\zeta_{\mathrm{t}}\right\}$ is a white noise with mean zero variance $\sigma^{2}$, then $\left\{Y_{t}\right\}$ is defined by $Y_{t}=\zeta_{t}+\beta_{1} \zeta_{t-1}+$ $\beta_{2} \zeta_{\mathrm{t}-2}+\ldots+\beta_{\mathrm{q}} \zeta_{\mathrm{t}-\mathrm{q}}$ is called a moving average process of order $\mathrm{q}$ and is denoted by $\mathrm{MA}(\mathrm{q})$. If the process $\left\{\mathrm{Y}_{\mathrm{t}}\right\}$ is given by $\mathrm{Y}_{\mathrm{t}}=\mathrm{a}_{1} \mathrm{Y}_{\mathrm{t}-1}+\mathrm{a}_{2} \mathrm{Y}_{\mathrm{t}-2}+\ldots+\mathrm{a}_{\mathrm{p}} \mathrm{Y}_{\mathrm{t}-\mathrm{p}}+\zeta_{\mathrm{t}}$ is called an auto-regressive process of order $\mathrm{p}$ and is denoted by $\mathrm{AR}(\mathrm{p})$. Models that are combination of $\mathrm{AR}$ and $M A$ models are known as ARMA models. An $\operatorname{ARMA}(\mathrm{p}, \mathrm{q})$ model is defined as $\mathrm{Y}_{\mathrm{t}}=\mathrm{a}_{1} \mathrm{Y}_{\mathrm{t}-1}+\mathrm{a}_{2} \mathrm{Y}_{\mathrm{t}-2}+\ldots+\mathrm{a}_{\mathrm{p}} \mathrm{Y}_{\mathrm{t}-\mathrm{p}}+\zeta_{1}$ $+\beta_{1} \zeta_{\mathrm{t}-1}+\beta_{2} \zeta_{\mathrm{t}-2}+\ldots+\beta_{\mathrm{q}} \zeta_{\mathrm{t}-\mathrm{q}}$, where, $\mathrm{Y}_{\mathrm{t}}$ is the original series, for every $\mathrm{t}$, we assume that $\zeta_{\mathrm{t}}$ is independent of $\mathrm{Y}_{\mathrm{t}}$ $1, Y_{t-2}, \ldots, Y_{t-p}$. A time series $\left\{Y_{t}\right\}$ is said to follow an integrated autoregressive moving average (ARIMA) model if the $\mathrm{d}^{\text {th }}$ difference $\mathrm{W}_{\mathrm{t}}=\nabla^{\mathrm{d}} \mathrm{Y}_{\mathrm{t}}$ is a stationary ARMA process. If $\left\{\mathrm{W}_{\mathrm{t}}\right\}$ follows an $\operatorname{ARMA}(\mathrm{p}, \mathrm{q})$ model, we say that $\left\{\mathrm{Y}_{\mathrm{t}}\right\}$ is an $\operatorname{ARIMA}(\mathrm{p}, \mathrm{d}, \mathrm{q})$ process. Fortunately, for practical purposes, we can usually take $\mathrm{d}$ $=$ lor at most 2. Consider then an $\operatorname{ARIMA}(\mathrm{p}, 1, \mathrm{q})$ process. With $\mathrm{W}_{\mathrm{t}}=\mathrm{Y}_{\mathrm{t}}-\mathrm{Y}_{\mathrm{t}-1}$, we have, $\mathrm{W}_{\mathrm{t}}=\mathrm{a}_{1} \mathrm{~W}_{\mathrm{t}-1}+\mathrm{a}_{2} \mathrm{~W}_{\mathrm{t}-}$ ${ }_{2}+\ldots+\mathrm{a}_{\mathrm{p}} \mathrm{W}_{\mathrm{t}-\mathrm{p}}+\zeta_{1}+\beta_{1} \zeta_{\mathrm{t}-1}+\beta_{2} \zeta_{\mathrm{t}-2}+\ldots+\beta_{\mathrm{q}} \zeta_{\mathrm{t}-\mathrm{q}}$.

\section{Box-Jenkins Method}

The influential work of Box-Jenkins (Box and Jenkins, 1970) shifted professional attention away from the stationary serially correlated deviations from deterministic trend paradigm toward the $\operatorname{ARIMA}(p, d, q)$ paradigm. It is popular because it can handle any series, stationary or not with or without seasonal elements. The basic steps in the Box-Jenkins methodology consist of the following five steps.

\section{Preliminary Analysis}

Create conditions such that the data at hand can be considered as the realization of a stationary stochastic process.

\section{Identification of a Tentative Model}

Specify the orders $p, d, q$ of the ARIMA model so that it is clear the number of parameters to estimate. Empirical autocorrelation functions play an extremely important role to recognize the model. 


\section{Estimation of the Model}

The next step is the estimation of the tentative ARIMA model identified in step-2. By maximum likelihood method, we estimate the parameters of the model.

\section{Diagnostic Checking}

Check if the model is a good one using tests on the parameters and residuals of the model.

\section{Forecasting}

If the model passes the diagnostics step, then it can be used to interpret a phenomenon, forecast.

\section{Ljung-Box Test}

Ljung-Box (Ljung and Box, 1978) test can be used to check autocorrelation among the residuals. If a model fit well, the residuals should not be correlated and the correlation should be small. In this case the null hypothesis is $\mathrm{H}_{0}: \rho_{1}(\mathrm{e})=\rho_{2}(\mathrm{e})=\ldots=\rho_{\mathrm{k}}(\mathrm{e})=0$ is tested with the Ljung-Box statistic, $Q^{*}=N(N+1) \sum_{i=1}^{k}(N-k) \rho_{k}^{2}(e)$, where, $\mathrm{N}$ is the number of observation used to estimate the model. This statistic $\mathrm{Q}^{*}$ approximately follows the chi-square distribution with $(k-q) d f$, where $q$ is the number of parameter should be estimated in the model. If $Q^{*}$ is large (significantly large from zero), it is said that the residuals of the estimated model are probably autocorrelated. Thus, one should then consider reformulating the model.

\section{Model Selection Criteria}

Before forecasting it is necessary to estimate the Time Series model and evaluating the performance of the best fitted model. There are many summary statistics available in literature for evaluating the forecast errors of any Time Series or Econometric model. Here, an attempt is made to identify the best models for jute production in Bangladesh using the following contemporary model selection criteria, such as RMSPE, MPFE and TIC.

\section{Root Mean Square Error Percentage (RMSPE)}

Root Mean Square Error Percentage (RMSPE) is defined as:

$$
R M S P E=\sqrt{\frac{1}{T} \sum_{t=1}^{T}\left(\frac{Y_{t}^{f}-Y_{t}^{a}}{Y_{t}^{a}}\right)^{2}}
$$

where, $Y_{t}^{f}$ is the forecast value in time $\mathrm{t}$ and $Y_{t}^{a}$ is the actual value in time $t$.

\section{Mean Percent Forecast Error (MPFE)}

Hossain et al. (2006) used the Mean Percent Forecast Error (MPFE) which is defined as:

$$
\text { MPFE }=\frac{1}{T} \sum_{t=1}^{T}\left(\frac{Y_{t}^{a}-Y_{t}^{f}}{Y_{t}^{a}}\right)
$$

where, $Y_{t}^{a}$ is the actual value in time $\mathrm{t}$ and $Y_{t}^{f}$ is the forecast value in time $t$.

\section{Theil Inequality Coefficient (TIC)}

Theil (1966) Inequality Coefficient (TIC) is defined as:

$$
T I C=\frac{\sqrt{\frac{1}{T} \sum_{t=1}^{T}\left(Y_{t}^{f}-Y_{t}^{a}\right)^{2}}}{\sqrt{\frac{1}{T} \sum_{t=1}^{T}\left(Y_{t}^{a}\right)^{2}}+\sqrt{\frac{1}{T} \sum_{t=1}^{T}\left(Y_{t}^{f}\right)^{2}}}
$$

where, $Y_{t}^{f}$ is the forecast value in time $\mathrm{t}$ and $Y_{t}^{a}$ is the actual value in time $t$.

\section{Results}

In the present times, production takes place by the combined forces of various factors of production such as land, labor, capital etc. Future production depends on the price, demand, technology etc. However, in this paper, it is trying to identify the Time Series model for forecasting the future production instead of finding the factors influenced production. Some statistical properties of the selected model also checked here. During the study period the average Jute production in Bangladesh is around 968116.7 tonnes per annum with a standard deviation 221700.5 tonnes. The maximum production was 1571019 tonnes occurred in the year 1986 and the minimum production was 711 thousand tonnes occurred in the year 1999. In this study, Augmented-Dickey-Fuller (ADF), Phillips-Perron (PP) and KwiatkowskiPhillips-Schmidt-Shin (KPSS) unit root test are used to check whether the data series is stationary or not. After first differencing the Augmented-Dickey-Fuller (ADF) test with $\operatorname{Pr}(|\tau| \geq-4.7666)<0.01$, Phillips-Perron (PP) test with $\operatorname{Pr}(|\tau| \geq-32.2337)<0.01$ and Kwiatkowski-Phillips-Schmidt-Shin (KPSS) unit root test with $\operatorname{Pr}(|\tau| \geq 0.1109)>0.1$ at $5 \%$ level of significance adequately declared that the data series is stationary which suggest that there is no unit root. The graphical representations of the original and first differenced series are presented in Fig. $1 \mathrm{a}$ and $\mathrm{b}$. 


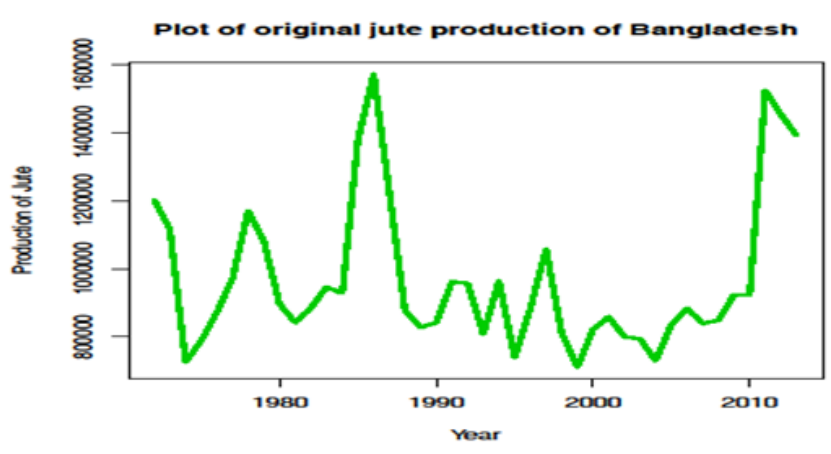

(a)

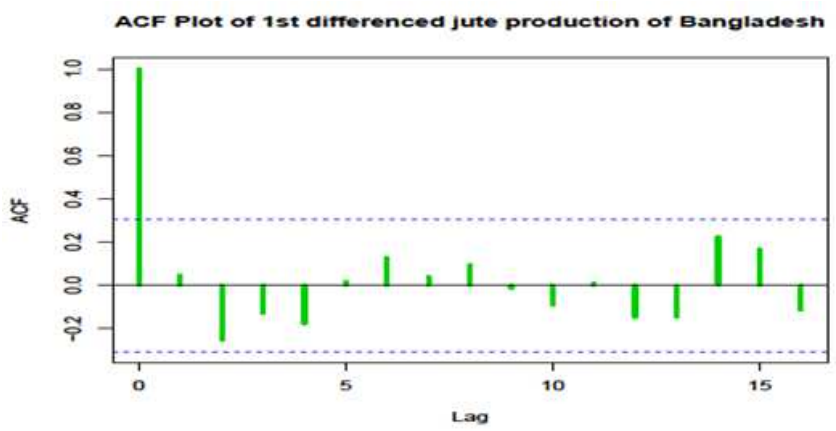

(c)

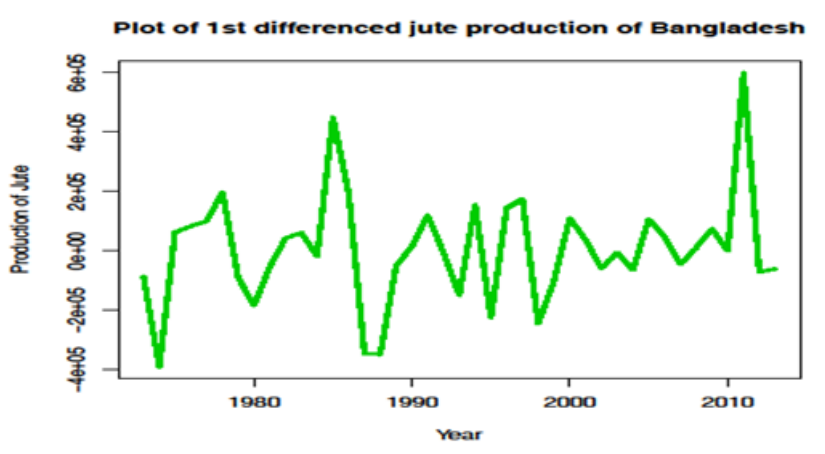

(b)

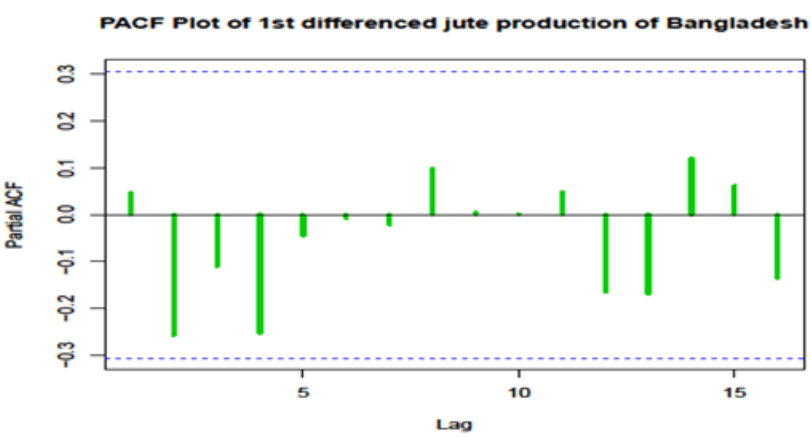

(d)

Fig. 1. (a) Time series (original series) plot, (b) Time series (1st differenced) plot (c) ACF and (d) PACF of 1st differenced jute production in Bangladesh

It is clear that the yearly jute production in Bangladesh fluctuated over the study period 1972-2013. The jute production started at about 1200 thousand tonnes in 1972 and reached a peak in 1986 of around 1571 thousand tones then it dropped dramatically up to the year 1990 and the production reached to around 841 thousand tones. After the year 2004 there was an upward trend in the jute production in Bangladesh, i.e., the variance is unstable which indicates the jute production data series is not stationary (Fig. 1a). However, it is clear that the first differenced jute production data series shows stable variance which indicates the data becomes stationary. To stabilize the variance and to make the data stationary first difference is enough that is difference order is 1 and it is said to be integrated of order 1 (Fig. 1b). The alternative positive and negative ACF (Fig. 1c) and exponentially decay PACF (Fig. 1d) indicates an autoregressive moving average process. Using the tentative procedure, it is clear that $\operatorname{ARIMA}(1,1,1)$ model with $\mathrm{AIC}=112.69, \mathrm{AIC}_{\mathrm{C}}=1113.34$ and $\mathrm{BIC}=1117.83$ is the best selected model for forecasting the jute production in Bangladesh. The estimates of the parameters of the fitted ARIMA $(1,1,1)$ model are shown in Table 1. Also, the value of the most useful "forecasting criteria" of the fitted model are shown in Table 1.

Several graphical representations of the residuals for the fitted ARIMA(1,1,1) model are presented in Fig. 2. They suggest that there is no significant pattern among the residuals and hence it can be reached a conclusion that there is no autocorrelation among the residuals. Also, the "Box-Pierce" test with $\operatorname{Pr}\left(\left|\chi_{1}^{2}\right| \geq 1.209\right)=0.2715$ and the "Ljung-Box" test with $\operatorname{Pr}\left(\left|\chi_{1}^{2}\right| \geq 1.2974\right)=0.2547$ at $5 \%$ level of significance strongly suggest to accept that there is no autocorrelation among the residuals of the fitted ARIMA $(1,1,1)$ model. Here "Histogram with Normal Curve" is used to check the normality assumption of the residuals of the fitted model. The Histogram with Normal Curve of the residuals of the fitted $\operatorname{ARIMA}(1,1,1)$ model is given in Fig. 2. Histogram with Normal Curve suggests that the residuals of the fitted $\operatorname{ARIMA}(1,1,1)$ model are approximately normally distributed. Therefore, it is clear that the fitted $\operatorname{ARIMA}(1,1,1)$ model is the best fitted model and adequately used to forecast the jute production in Bangladesh.

By using the best fitted model $\operatorname{ARIMA}(1,1,1)$, the forecasted jute production along with $95 \%$ confidence level for ten years are shown in Table 2.

The graphical comparison of the original series and the forecasted series is shown in Fig. 3. It is observed that the forecasted series (blue-color) fluctuated from the original series (dark-green-color) with a very small amount which shows the fitted series has the same manner of the original series (Fig. 3). Therefore, the forecasted series is really a better representation of the original jute production series in Bangladesh. 


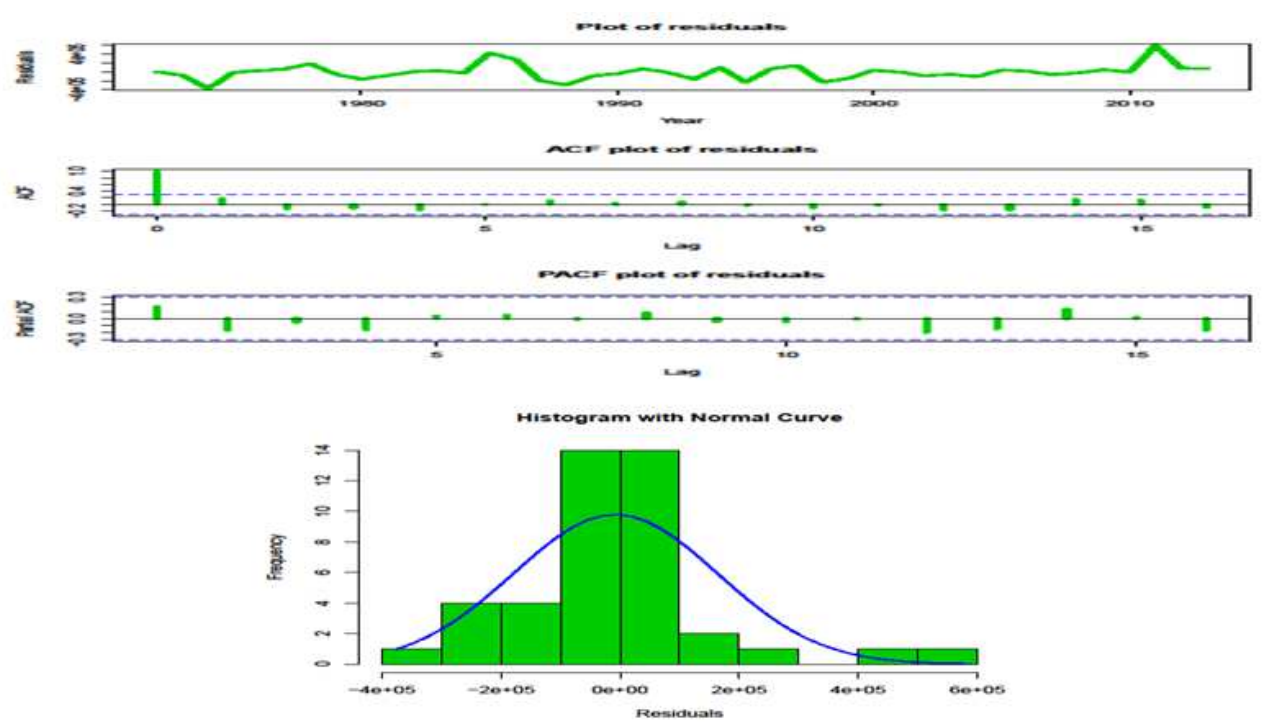

Fig. 2. Several plots of residual plots and histogram with normal curve

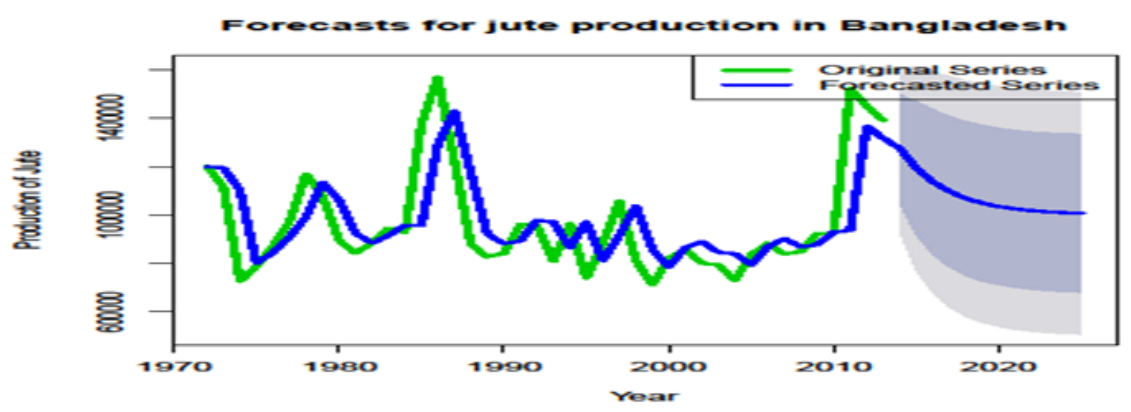

Fig. 3. Comparison between the original and forecast/ed jute production in Bangladesh

Table 1. Summary statistics and forecasting criteria of the fitted ARIMA $(1,1,1)$ model

\begin{tabular}{lllll}
\hline Coefficients & Estimates & Std. Error & t-value & p-value \\
\hline ar1 & 0.7051 & 0.1328 & 5.30949 & 0.05926 \\
mal & -1 & 0.0767 & -13.038 & 0.02437 \\
Forecasting criteria & MASE & RMSPE & MPFE & TIC \\
& 0.87881 & 0.16508 & -0.031 & 0.08547 \\
\hline
\end{tabular}

Table 2. Forecasted jute production in Bangladesh

\begin{tabular}{|c|c|c|c|}
\hline \multirow[b]{2}{*}{ Year } & \multicolumn{3}{|c|}{ Jute production (tonnes) } \\
\hline & Forecasted & LCL & UCL \\
\hline 2014 & 1276199 & 936685 & 1615713 \\
\hline 2015 & 1195250 & 775745 & 1614754 \\
\hline 2016 & 1138170 & 681476 & 1594865 \\
\hline 2017 & 1097923 & 622041 & 1573804 \\
\hline 2018 & 1069543 & 583176 & 1555909 \\
\hline 2019 & 1049532 & 557180 & 1541883 \\
\hline 2020 & 1035421 & 539523 & 1531320 \\
\hline 2021 & 1025472 & 527399 & 1523544 \\
\hline 2022 & 1018456 & 519011 & 1517901 \\
\hline 2023 & 1013509 & 513175 & 1513843 \\
\hline 2024 & 1010021 & 509099 & 1510943 \\
\hline 2025 & 1007561 & 506244 & 1508878 \\
\hline
\end{tabular}




\section{Conclusion}

The best selected Box-Jenkins ARIMA model for forecasting the jute productions in Bangladesh is $\operatorname{ARIMA}(1,1,1)$. From the comparison between the original series and forecasted series shows the same manner indicating fitted model are statistically well behaved to forecast jute productions in Bangladesh i.e., the models forecast well during and beyond the estimation period which reached at a satisfactory level. Thus, this model can be used for policy purposes as far as forecasts the jute production in Bangladesh. In future study the authors include others relevant factors of production such as price, demand, weather in the model.

\section{Acknowledgment}

The authors are grateful to the anonymous referee for a careful checking of the details and for helpful comments that improved this paper.

\section{Author's Contributions}

Md. Moyazzem Hossain: Design, Collected and checked the analyzed data and wrote the manuscript, contributed in interpreting data and the final art work.

Faruq Abdulla: Coordinated the study, analyzed data and wrote manuscript.

\section{Ethics}

The authors declare that this is an original research and do not have any ethical issues or copyrights conflict.

\section{Reference}

Abdullah, A.B.M., 2013. Challenges of 21 st Century: Global climate changes and jute baseddevelopment strategy of Bangladesh. Asiatic Society Bangladesh, Dhaka.

Hossain, M.Z., Q.A. Samad and M.Z. Ali, 2006. ARIMA model and forecasting with three types of pulse prices in Bangladesh: A case study. Int. J. Social Econom., 33: 344-353. DOI: $10.1108 / 03068290610651652$

Ghosh, B.K. and A. Jethi, 2013. Growth and instability in world jute production: A disaggregated analysis. Int. J. Electron. Commun. Technol., 4: 191-195.
Box, G. and G. Jenkins, 1970. Time Series Analysis: Forecasting and Control. 1st Edn., Holden-Day, San Francisco.

Environment, 2011. International jute study group. Fibre Res., 24: 21-26.

Ljung, G.M. and G.E.P. Box, 1978. On a measure of a lack of fit in time series models. Biometrika, 65: 297-303. DOI: 10.1093/biomet/65.2.297

Islam, M.R., M. Rana, M. Hoque, M.M.H.A. and M.K. Ahmed, 2013. Causes and consequences of labour unrest in jute mills of Khulna division in Bangladesh: An empirical study. Int. J. Business Management Rev., 1: 57-68.

Islam, M.S. and S.K. Ahmed, 2012. The impacts of jute on environment: An analytical review of Bangladesh. J. Env. Earth Sci., 2: 24-31.

Islam, M.S. and M. Alauddin, 2012. World production of jute: A comparative analysis of Bangladesh. Int. J. Management Bus. Studies, 2: 14-22.

Rahman, M.M., 2001. Policy and prospect of jute and allied fibers with special reference to Bangladesh. Bangladesh Institute of Labor Studies.

Rahman, M.M., A.K. Azad and M.L. Rahman, 1992. Irrigation in jute production. Jute Jute Fabrics Bangladesh, 18: 5-8.

Sikdar, M.F.S. and B.N. Banerjee, 1990. Jute Cultivation in India and Bangladesh: A Comparative Study. 1st Edn., Mittal Publications, New Delhi, ISBN-10: 8170992125, pp: 121.

Talukder, F.A.H. and M.A. Rahman, 1989. Jute seed testing: A step towards increase production. BJRI, Bangladesh.

Theil, H., 1966. Applied Economic Forecasting. 1st Edn., North-Holland Pub. Co., Amsterdam, pp: 474. 